\title{
Nurse managers
}

Citation for published version (APA):

Heckemann, B., Peter, K. A., Halfens, R. J., Schols, J. M., Kok, G., \& Hahn, S. (2017). Nurse managers:

Determinants and behaviours in relation to patient and visitor aggression in general hospitals. A qualitative study. Journal of Advanced Nursing, 73(12), 3050-3060. https://doi.org/10.1111/jan.13366

\section{Document status and date:}

Published: 01/12/2017

DOI:

10.1111/jan.13366

Document Version:

Publisher's PDF, also known as Version of record

\section{Document license:}

Taverne

\section{Please check the document version of this publication:}

- A submitted manuscript is the version of the article upon submission and before peer-review. There can be important differences between the submitted version and the official published version of record.

People interested in the research are advised to contact the author for the final version of the publication, or visit the DOI to the publisher's website.

- The final author version and the galley proof are versions of the publication after peer review.

- The final published version features the final layout of the paper including the volume, issue and page numbers.

Link to publication

\footnotetext{
General rights rights.

- You may freely distribute the URL identifying the publication in the public portal. please follow below link for the End User Agreement:

www.umlib.nl/taverne-license

Take down policy

If you believe that this document breaches copyright please contact us at:

repository@maastrichtuniversity.nl

providing details and we will investigate your claim.
}

Copyright and moral rights for the publications made accessible in the public portal are retained by the authors and/or other copyright owners and it is a condition of accessing publications that users recognise and abide by the legal requirements associated with these

- Users may download and print one copy of any publication from the public portal for the purpose of private study or research.

- You may not further distribute the material or use it for any profit-making activity or commercial gain

If the publication is distributed under the terms of Article $25 \mathrm{fa}$ of the Dutch Copyright Act, indicated by the "Taverne" license above, 


\title{
Nurse managers: Determinants and behaviours in relation to patient and visitor aggression in general hospitals. A qualitative study
}

\author{
Birgit Heckemann $^{1,2}$ (D) | Karin A Peter ${ }^{1}$ | Ruud JG Halfens ${ }^{3}$ | Jos MGA Schols ${ }^{4}$ | \\ Gerjo Kok ${ }^{5}$ | Sabine Hahn ${ }^{1}$ (C)
}

${ }^{1}$ Department of Applied Research \& Development in Nursing, Bern University of Applied Sciences, Bern, Switzerland

${ }^{2}$ Care and Public Health Research Institute (CAPHRI), Maastricht University,

Maastricht, the Netherlands

${ }^{3}$ Department of Health Services Research, Care and Public Health Research Institute (CAPHRI), Maastricht University,

Maastricht, the Netherlands

${ }^{4}$ Department of Family Medicine and Department of Health Services Research, CAPHRI - Care and Public Health Research Institute (CAPHRI), Maastricht University, Maastricht, the Netherlands

${ }^{5}$ School of Psychology and Neuroscience, Department of Work and Social Psychology, Maastricht University, Maastricht, the Netherlands

\section{Correspondence}

Birgit Heckemann, Department of Applied Research \& Development in Nursing, Bern University of Applied Sciences, Bern, Switzerland.

Email: birgit.heckemannn@bfh.ch

Funding information

This study was financially supported by Bern University of Applied Sciences, Health

Division, Bern, Switzerland

\begin{abstract}
Aim(s): To explore nurse managers' behaviours, attitudes, perceived social norms, and behavioural control in the prevention and management of patient and visitor aggression in general hospitals.

Background: Patient and visitor aggression in general hospitals is a global problem that incurs substantial human suffering and organizational cost. Managers are key persons for creating low-aggression environments, yet their role and behaviours in reducing patient and visitor aggression remains unexplored.
\end{abstract}

Design: A qualitative descriptive study underpinned by the Reasoned Action Approach.

Method(s): Between October 2015-January 2016, we conducted five focus groups and 13 individual interviews with nurse leaders in Switzerland. The semi-structured interviews and focus groups were recorded, transcribed, and analysed in a qualitative content analysis.

Findings: We identified three main themes: (i) Background factors: "Patient and visitor aggression is perceived through different lenses"; (ii) Determinants and intention: "Good intentions competing with harsh organizational reality"; (iii) Behaviours: "Preventing and managing aggressive behaviour and relentlessly striving to create low-aggression work environments".

Conclusion(s): Addressing patient and visitor aggression is difficult for nurse managers due to a lack of effective communication, organizational feedback loops, protocols, and procedures that connect the situational and organizational management of aggressive incidents. Furthermore, tackling aggression at an organizational level is a major challenge for nurse managers due to scant financial resources and lack of interest. Treating patient and visitor aggression as a business case may increase organizational awareness and interest. Furthermore, clear communication of expectations, needs and resources could optimize support provision for staff.

\section{KEYWORDS}

attitudes, behaviours, nurse manager, patient aggression, patient violence, perceived norms, qualitative research, visitor aggression, workplace safety 


\section{INTRODUCTION}

Nurses are a staff group at risk of experiencing verbal or physical aggression in the workplace (Bentley, Catley, Forsyth, \& Tappin, 2014; Spector, Zhou, \& Che, 2014; The Health and Safety Executive, 2015a). Patients and visitors are the primary source of aggression in health care (Spector et al., 2014). Approximately 60\% of all nurses worldwide report having experienced nonphysical or verbal violence and $30 \%$ have been exposed to physical aggression (Spector et al., 2014). Although the majority of patient and visitor aggression (PVA) occurs in mental health and accident and emergency departments, all clinical settings are affected (Edward, Ousey, Warelow, \& Lui, 2014; Hahn et al., 2008). This study focused on the general hospital setting. PVA is a complex phenomenon that occurs in many forms such as

[...] insults, threats, or physical or psychological aggression exerted by people from outside the organization, including customers and clients, against a person at work, that endangers their health, safety or well-being. There may be a sexual or racial dimension to the violence. Aggressive or violent acts take the form of:

- Uncivil behaviour - lack of respect for others

- Physical or verbal aggression - intention to injure

- Assault - intention to harm the other person. [...]

(European Agency for Safety and Health at Work,

2002).

PVA has long been recognized as a problem by policy makers. Efforts in research and politics to lower incidence rates have resulted in a plethora of recommendations and guidance on how to address PVA (Department of Health and Human Services, 2015; The Health and Safety Executive, 2015b). Despite these initiatives, PVA incidence remains high and the ensuing human and financial costs are a major burden on health systems (Lanctôt \& Guay, 2014; The National Audit Office, 2003). Nurse managers are key persons for establishing safer, supportive, low-aggression work environments (Farrell, Touran, \& Siew-Pang, 2014; Feather, Ebright, \& Bakas, 2015; McKenna, 2008). Their beliefs, attitudes and behaviours regarding PVA are important for effective PVA management and staff protection (Blando et al., 2012; Catlette, 2005; Gates, Gillespie, Smith, Rode, Kowalenko, and Smith, 2011). Supportive managers increase the safety of work environments (Blando et al., 2012). However, some research evidence shows that nurse managers may underreport or ignore PVA and staff protection to prioritize consumer friendliness or to protect a public image (Gates, Gillespie, Smith, et al., 2011; Renker, Scribner, \& Huff, 2015; Wolf, Delao, \& Perhats, 2014). Despite their important role in creating low-aggression work environments, nurse managers' beliefs, attitudes, and behaviours remain to date unexplored.

\section{Why is this research needed?}

- Incidence of patient and visitor aggression in health care remains high and incurs substantial human suffering and organizational cost.

- Nurse managers are key persons in the prevention and management of patient and visitor aggression, but their behaviours, attitudes, and roles in the clinical setting with regard to aggressive incidents remain underexplored.

\section{What are the key findings?}

- Patient and visitor aggression is perceived from a situational and/or organizational perspective; both entail specific behaviours.

- Communication between staff nurses and management should be strengthened. Formal incident reports in particular are to date mainly used for statistical purposes, but should also serve as a tool to enhance communication between nursing staff and management.

- Addressing patient and visitor aggression at an organizational level is particularly challenging due to a lack of awareness in the organization and scant financial resources.

\section{How should the findings be used to influence policy/practice/research/education?}

- Feedback loops, structured information exchange and data collection on patient and visitor aggression in the nursing team potentially improve its prevention and management.

- Nurse managers should develop prowess in presenting a strong business case for an anti-aggression strategy, comprising number of aggressive incidents, costs incurred, potential savings, and benefits to raise awareness in organizations that prioritize economic considerations.

\section{1 | Background}

Underpinned by the Reasoned Action Approach (RAA) (Fishbein \& Ajzen, 2010), this study explores nurse managers' beliefs, attitudes, and behaviours in relation to the prevention and management of PVA in the general hospital context. The RAA is the most recent version of a model that has been developed, refined, and measured over the course of 45 years (Ajzen, 1991; Fishbein \& Ajzen, 1975). The RAA assumes that human behaviour is the result of a causal sequence of decision-making processes. Decision-making is affected by certain determinants (i.e., attitudes, perceived social norms, perceived behavioural control, and their underlying beliefs) and background factors (e.g., training, professional position, and experience, etc.). These factors and determinants influence a person's 


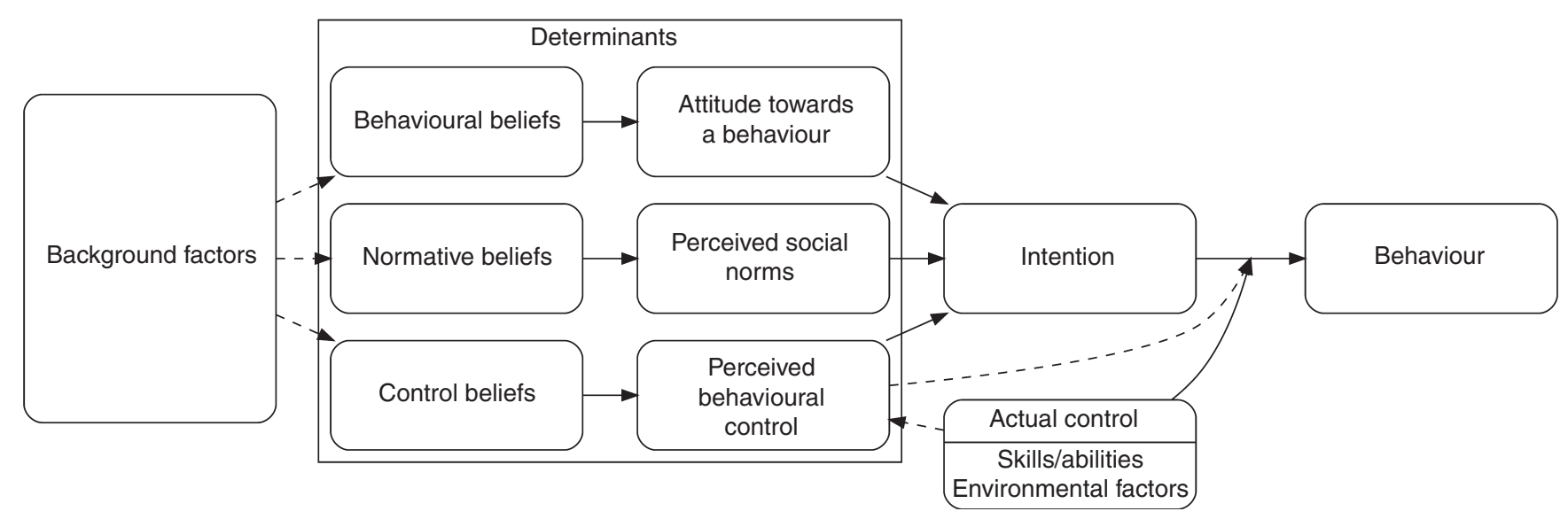

FIGURE 1 The reasoned action approach, adapted from Fishbein \& Ajzen, 2010, p. 22

intentions and, eventually, their actual behaviour. Figure 1 shows the relationship between background factors, determinants, intentions and behaviours according to the RAA model (Fishbein \& Ajzen, 2010).

The RAA helps to identify the salient beliefs, i.e., attitudinal, normative, and control beliefs, which influence behaviour. Furthermore, it facilitates understanding which of those salient beliefs need to be changed to promote the desired behaviour, in this case the optimal prevention and management of PVA (Peters, 2014).

Fishbein and Ajzen (2010) describe a formative research approach, which, among other steps, involves the elicitation of salient beliefs. We applied this qualitative elicitation procedure, because to date managers' underlying beliefs with regard to PVA have not been scientifically documented.

\section{2 | Aims}

The aim of this study was to explore: (i) behaviours of nurse managers in the prevention and management of PVA in an acute hospital setting; (ii) their intentions and salient determinants; and (iii) relevant background factors.

\section{DESIGN}

This study comprised semi-structured focus groups and individual interviews. Data were processed in a qualitative content analysis according to Schreier (2012, 2014). The data collection, analysis, and interpretation were guided by the RAA (Fishbein \& Ajzen, 2010).

\section{1 | Sample/Participants}

\subsection{1 | Participants and population}

Our target population consisted of nurse managers working in general hospitals in the German-speaking regions of Switzerland. We included ward managers, divisional managers, and directors of nursing, and their respective deputies.

\subsection{2 | Sampling strategy}

We chose a convenience sampling strategy and invited nursing directors of 15 hospitals from in the authors' professional networks to participate in the study. An invitation, information material and registration forms were emailed in October 2015. Those directors of nursing who wanted to support the study distributed the invitation among their colleagues. We did not specifically ask for inclusion of what typically are considered higher (e.g., emergency departments, intensive care) or lower-risk (e.g., maternity) wards.

\subsection{3 | Setting}

Six general hospitals in the German speaking regions of Switzerland agreed to participate in the study. In addition to accident and emergency services, the hospitals provided medical, intensive, intermediate, surgical as well as gynaecology and maternity care. Four of the participating hospitals had between 200-275 beds; one had 360 and one approximately 1000 beds.

\subsection{Data collection}

All interviews and focus groups were conducted in German. Divisional directors and directors of nursing took part in individual interviews, while ward managers were interviewed in focus groups. This approach enabled us to include a maximum number of managers with our given resources, because in any hospital the number of ward managers will exceed the number of divisional managers and directors.

\subsection{1 | Individual interviews}

As per each participant's preference, we conducted the individual interviews either face-to-face $(n=4)$ (by KAP) or by telephone $(n=11)$ (by BH) between 26 October 2015-23 November 2015. Interviews lasted between 14-71 min. Appointments for the interviews were scheduled via email exchange between participants and $\mathrm{BH}$. 


\subsubsection{Focus groups}

Five semi-structured face-to-face focus groups with a minimum of four and a maximum of seven participants took place between 2 February 2015-2 December 2016. The focus group interviews took place in private meeting rooms at participating hospitals. During the interviews, only the moderator (KAP) and the participants were present.

\subsection{3 $\quad$ The topic guide}

$\mathrm{BH}, \mathrm{SH}, \mathrm{KAP}$ developed the topic guide that facilitated the data collection. The content of the guide was tested during two individual interviews $(\mathrm{BH})$ and one focus group (KAP). $\mathrm{BH}$ and KAP discussed the guide and considered it suitable for the study. Table 1 shows the key topics and questions of the interview guide.

All individual interviews and focus groups were digitally recorded and transcribed according to a transcription guide. To ensure the quality of the transcripts, the written record of the interviews was checked against the digital recording and typing errors were corrected $(\mathrm{BH})$.

\section{3 | Ethical considerations}

The study was conducted in compliance with Swiss national legal and regulatory requirements. The study protocol was reviewed by

TABLE 1 Topic guide

\begin{tabular}{|c|c|}
\hline Topic area & Key questions \\
\hline $\begin{array}{l}\text { Management of PVA } \\
\text { (perceptions, beliefs, } \\
\text { attitudes, perceived } \\
\text { behavioural control) }\end{array}$ & $\begin{array}{l}\text { 1. How do you react when PVA occurs in } \\
\text { you area of responsibility? } \\
\text { 2. What is important to you in the } \\
\text { management of PVA? (With regards to } \\
\text { your staff and to patients or visitors) } \\
\text { 3. Are your values shared across the } \\
\text { organization? } \\
\text { 4. How important do you consider the topic } \\
\text { PVA within your organization? }\end{array}$ \\
\hline $\begin{array}{l}\text { Prevention of PVA } \\
\text { (social norms, } \\
\text { perceived behavioural } \\
\text { control) }\end{array}$ & $\begin{array}{l}\text { 1. What is particularly important in your role } \\
\text { in the prevention of PVA? } \\
\text { 2. Where do you see room for improvement? } \\
\text { 3. In your particular role, how do you } \\
\text { consider your chances of achieving } \\
\text { change? } \\
\text { 4. Where do you see barriers for change? }\end{array}$ \\
\hline
\end{tabular}

the local Swiss ethical board, which confirmed that the study plan did not warrant a full ethical application, as it did not fall under the Swiss Federal Act on Research Involving Human Beings. All participants gave informed written consent. Moreover, to ensure confidentiality, all personal information was de-identified in the interview transcripts and other documentation.

\subsection{Data analysis}

The interviews were processed in a qualitative content analysis according to Schreier (2012, 2014). The language was assumed to carry little or no underlying meaning and the data were thus interpreted at a low level of inference with a focus on facts rather than on detecting latent meaning (Sandelowski, 2000). The RAA was used to provide an initial template to guide the coding process (see Table S1 for the initial and Table S2 for the final coding templates). The template comprised the RAA's factors and determinants (Figure 1), as well as definitions of and examples for each category or code. While all authors contributed to the analysis (cf. Table 2) $\mathrm{BH}$ took overall responsibility. The analysis comprised five cycles (Table 2). The transcripts were managed with MAXQDA software (VERBI GmbH, Berlin, Germany) for computer-assisted qualitative data analysis.

\section{5 | Valitidy and reliability/rigour}

The inclusion of various hospitals, clinical specialties and different management levels ensured the veracity of our findings. The diversity in our sample enabled us to access a wide range of perspectives on the topic. This study is theoretically grounded in a theoretical framework, the RAA (Fishbein \& Ajzen, 2010). The theoretical grounding enables critical review of and contextualizing the findings in a particular school of thought. Furthermore, discussions among the authors of this study during the different stages of data analysis added to the dependability of our results. Yet as with all qualitative research, the transferability of this study will be limited (Graneheim \& Lundman, 2004). To mitigate this risk, we endeavoured to be precise with our description of the setting and sample and used illustrative quotes from the interviews to support our findings.

TAB LE 2 Coding plan and coding process (Schreier, 2012, 2014)

\begin{tabular}{|c|c|c|c|}
\hline Cycle & Coding phase & Main coder & Review \\
\hline Preparation for coding & Developing initial template based on RAA (Fishbein \& Ajzen, 2010) & $\mathrm{BH}$ & Definition of codes (SH, GK, RH; JS) \\
\hline Cycle 1 (Theory driven) & Trial and adaptation of the initial coding template & $\mathrm{BH}$ & Coding frame (SH, GK, RH; JS) \\
\hline Cycle 2 (Data driven) & $\begin{array}{l}\text { Structural coding of all interviews, condensing meaning of coded } \\
\text { units in memos } \\
\text { (MacQueen, McLellan-Lemal, Bartholow, \& Milstein, 2008) }\end{array}$ & $\mathrm{BH}$ & $\begin{array}{l}\text { Coded text segments, definition of } \\
\text { codes and memos (SH, FJST) }\end{array}$ \\
\hline Cycle 3 (Data driven) & Splitting and splicing of data (Dey, 1993) & $\mathrm{BH}$ & \\
\hline Cycle 4 (Data driven) & Linking of data (Dey, 1993) & $\mathrm{BH}$ & Results (SH, FJST, GK) \\
\hline Cycle 5 (Theory driven) & Interpretation and identification of themes & $\mathrm{BH}$ & Interpretation (SH, FJST) \\
\hline
\end{tabular}




\section{FINDINGS}

Forty managers from across three management levels took part in this study.

Twenty-seven ward managers ( 21 female, six male) were included in the focus groups. Eight divisional managers (four female, four male) from various clinical specialities (Table 3 ), as well as five directors of nursing (four female, one male) were interviewed individually.

The study findings are presented under three main themes: (i) Background factors: PVA is perceived through different lenses, (ii) Determinants and intentions: "Good intentions competing with harsh organizational reality", (iii) Behaviours: "Managing aggressive behaviours and relentlessly striving to create safer work environments".

Theme 1: Background factors: "PVA is perceived through different lenses"

\section{1 | Personal factors}

All participants were qualified nurses with one to several decades of professional experience in health care. While some participants,

TABLE 3 Clinical specialities: divisional and ward managers

\begin{tabular}{|lll|}
\hline Department & $\begin{array}{l}\text { Divisional } \\
\text { managers } \\
(\boldsymbol{n}=\mathbf{8})^{\mathbf{b}}\end{array}$ & $\begin{array}{l}\text { Ward } \\
\text { managers } \\
(\boldsymbol{n}=\mathbf{2 7})\end{array}$ \\
\hline $\begin{array}{l}\text { Accident and emergency } \\
\text { (including ambulance services) }^{\mathrm{a}}\end{array}$ & 0 & 5 \\
\hline $\begin{array}{l}\text { Intermediate care } \\
\text { General surgery }\end{array}$ & 1 & 2 \\
\hline General medicine & 2 & 3 \\
\hline Intensive care & 4 & 6 \\
\hline Interdisciplinary care & 0 & 3 \\
\hline Nephrology and dialysis & 2 & 4 \\
\hline Obstetrics, gynaecology, and & 0 & 1 \\
\hline maternity & 1 & 2 \\
\hline Optimizing nursing care & 2 & 0 \\
\hline Palliative care and medicine & 0 & 1 \\
\hline
\end{tabular}

aIn Switzerland, ambulance services may be integrated with accident and emergency departments.

${ }^{\mathrm{b}}$ Three divisional managers were responsible for more than one division. typically at higher management levels, had no recent experience of PVA, some ward managers, particularly those working in high-risk areas such as accident and emergency departments, intensive care or medical wards, reported experiencing PVA as part of their everyday work:

"[On our ward] it is actually both visitors and patients [who are aggressive. We experience] also a lot of verbal aggression... We obviously also have physical aggression, but what happens every day are verbal attacks" (FG3, B2)

All participants had experienced verbal or physical PVA at some point in their careers and perceived PVA to be a drain on resources and a disruption to care delivery. Although PVA was seen as an unavoidable part of nursing practice, managers considered aggressive behaviour against nursing staff unacceptable.

Since participants were recruited from three different management levels, their job descriptions and experience of PVA varied. Ward managers oversaw the day-to-day running of their respective ward or unit, provided patient care and ensured the quality of care and service delivery. The divisional managers were involved in all aspects of service coordination, development, and performance. They were also the link between ward staff and the nursing directorate, as they maintained close contact with ward managers and relayed information about serious PVA incidents to the nursing directorate. Directors of nursing were engaged in planning, developing and directing the overall operation of the nursing divisions in accordance with legal requirements and guidelines. Depending on their professional role, frequency of patient contact and communication links with superiors, participants perceived PVA through different "lenses" (Figure 2). Those participants with frequent exposure to PVA regarded it primarily through a "situational lens", with a focus on how to deal with aggressive situations at the ward level. In contrast, managers with less direct exposure, such as divisional directors and directors of nursing were prone to view PVA through the "organizational lens". They focussed on issues such as improvement of the organizational structures to deal with future challenges:

"it is my role to recognize issues and to develop instruments. I am convinced that in 5-10 years' time, when

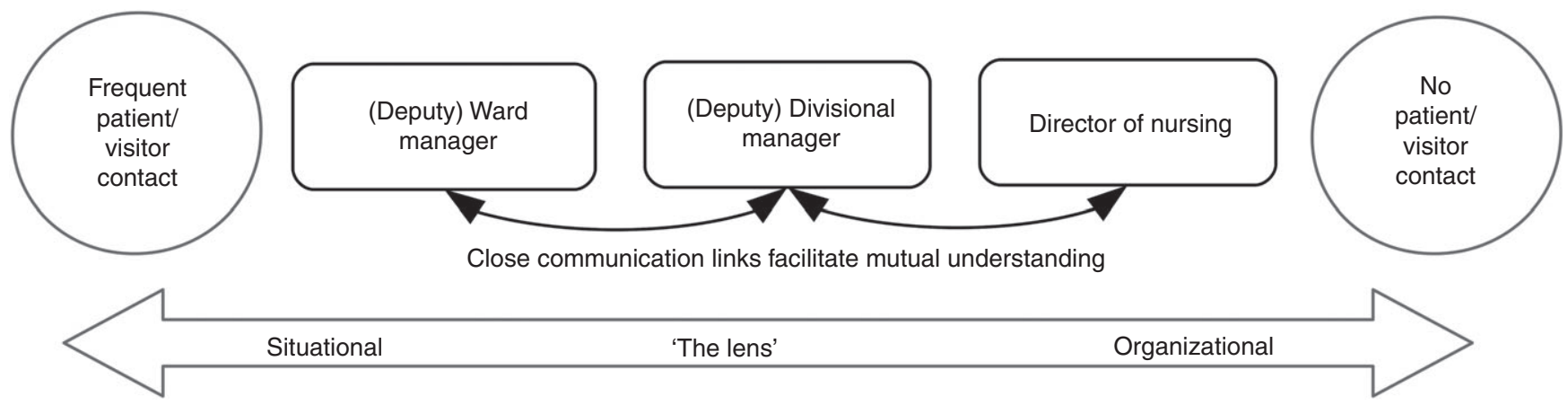

FIGURE 2 "PVA is perceived through different lenses" 
the percentage of elderly people is even higher, we will be confronted with phenomena like confusion etc. to a much larger extent" (IV11)

However, divisional directors and directors of nursing emphasized that close communication links with clinical staff provided valuable insight into the situational aspects of PVA management.

\section{2 | Organizational factors}

The level of organizational support against PVA differed between hospitals. Security services were generally available on site in the larger hospitals. Aftercare such as peer counselling or expert support for staff was accessible if needed. Furthermore, staff training courses to improve skills and knowledge in relation to PVA were available in all hospitals. However, as a routine, due to scant resources, often only staff working in emergency departments and other high-risk areas received this training. Some participants reported that their hospitals had official policies, such as protocols for the prevention and management of delirium, that had been fully implemented and had effectively reduced PVA. However, several ward managers described how insufficient implementation or knowledge about the protocols among physicians resulted in preventable incidents of PVA. Some, but not all organizations had an official PVA reporting system, yet particularly some ward managers questioned the effectiveness of such a reporting system, because:

"I motivate my colleagues to fill out a reporting form [after PVA incidents] and forward it. [.. .] I don't know in which drawer it disappears (all participants laughing)" (FG3)

The ward managers suspected that incident forms were used for statistical purposes only, because reporting evoked neither feedback nor visible actions from senior management.

Theme 2: Determinants and intentions: "Positive intent competing against harsh organizational reality"

The data analysis revealed that managers showed several attitudes and beliefs that related to particular behaviours. All participants showed a positive attitude towards engaging in behaviours to prevent PVA and to manage aggressive incidents as and when they occurred. In contrast, their intent to take action to effect change at the organizational level was weak due to limited perceived behavioural control. Table 4 shows how the competing determinants (compare RAA, Figure 1) affected the participants' intentions.

All managers expressed the belief that it is essential to care for nursing staff and to show interest in their concerns, because:

\section{"[...] I believe that it is truly most important that staff} are primarily well looked after, that they are being taken seriously [...]" (FG5)

This belief translated into a positive attitude and intentions towards behaviours that ensured staff were cared for if PVA incidents happened, because as:

"[managers] have a general responsibility to protect in an emergency situation. [.. .] And, I think that's the most important thing to really take on this mandate to protect seriously and not to trivialize [PVA incidents by saying]: 'Come on, that was not so bad' or something like that. So I think the employees should feel safe in their workplace [...]" (IV3)

The managers' perceived social norm was that staff expected their support. Maintaining close communication links between managers and ward nurses as well as managers' frequent presence on the wards were important for delivering this support if needed. Yet this was also a balancing act. The managers pointed out that due to their heavy workload they had to consider carefully the extent of involvement in the management of PVA. Managers were less optimistic about their perceived behavioural control. Introducing organizational measures to improve the management or prevention of PVA

TABLE 4 Determinants and intentions

\begin{tabular}{|c|c|}
\hline Determinants & $\begin{array}{l}\text { Managers' intention to act: } \\
\text { Positive }(+) \text { or negative/low (-) }\end{array}$ \\
\hline \multicolumn{2}{|l|}{ Managers' attitude (good-bad) } \\
\hline $\begin{array}{l}\text { 1. It is important to ensure staff } \\
\text { safety and well-being } \\
\text { (duty of care) } \\
\text { 2. It is important to talk about } \\
\text { PVA and to report incidents } \\
\text { 3. It is important to learn from } \\
\text { PVA incidents }\end{array}$ & $\begin{array}{l}+ \text { To take measures that } \\
\text { ensure staff safety } \\
+ \text { To disseminate information } \\
\text { about (severe) incidents } \\
\text { throughout the organization } \\
+ \text { To reflect on incidents, to } \\
\text { design and implement } \\
\text { protocols and procedures for } \\
\text { the prevention and } \\
\text { management of PVA }\end{array}$ \\
\hline \multicolumn{2}{|c|}{ Managers' normative beliefs (positive-negative) } \\
\hline $\begin{array}{l}\text { 1. Staff expect manager's support } \\
\text { 2. It is important that staff only } \\
\text { involve superiors if they are } \\
\text { unable to manage PVA within } \\
\text { the team }\end{array}$ & $\begin{array}{l}\text { To prioritize PVA as a topic, } \\
\text { to be present on wards and } \\
\text { approachable for staff } \\
\text { members } \\
+ \text { To provide adequate staff } \\
\text { support despite competing } \\
\text { job demands and high work } \\
\text { load in management }\end{array}$ \\
\hline
\end{tabular}

Managers' perceived behavioural control beliefs (high-low)

1. Standards/protocols/support, e.g., sitters, staff training not always implemented or accessible

2. Financial and human resources for the prevention of PVA are lacking or not allocated

3. Change is possible within the nursing team but challenging and time-consuming within the organization 
was regarded as a particular challenge, mainly due to financial constraints. While ward managers described their direct supervisors as benevolent and open to discussing initiatives to address PVA, suggestions were generally not considered if they incurred financial or other costs. Furthermore, managers across all management levels believed that PVA was generally not a prioritized topic in their organization. In particular, divisional managers and directors of nursing described initiatives to achieve organization-wide change, such as the introduction of protocols or securing funds to increase the safety of the physical environment, as challenging and time consuming, because:

"[...] up there [in higher management] there is little insight [into the problem of PVA], [...] most certainly amongst those people who ultimately decide about resource allocation." (IV4)

Due to the low perceived behavioural control, the intention to get involved in addressing PVA at the organizational level appeared to be weak in most managers. Nevertheless, some participants were strongly internally motivated to address PVA. These managers perceived the issue to be most relevant and had thus firm intentions and strategic plans to address PVA at an organizational level.

Theme 3: Behaviours: "Preventing and managing aggressive behaviour and relentlessly striving to create a safer work environment"

Managers' engagement in behaviours aimed at preventing and managing PVA varied. Several managers primarily engaged in behaviours associated with the prevention of PVA in individual cases or in the situational management of PVA. Others, typically higherlevel managers with strong intentions to address PVA at situational and organizational level, were more proactive. They visited and observed wards at busy times to identify potential issues in workflow or patient-staff interaction, or approached ward staff to discuss PVA. These managers stressed that addressing PVA at an organizational level required a lot of perseverance and determination, because:

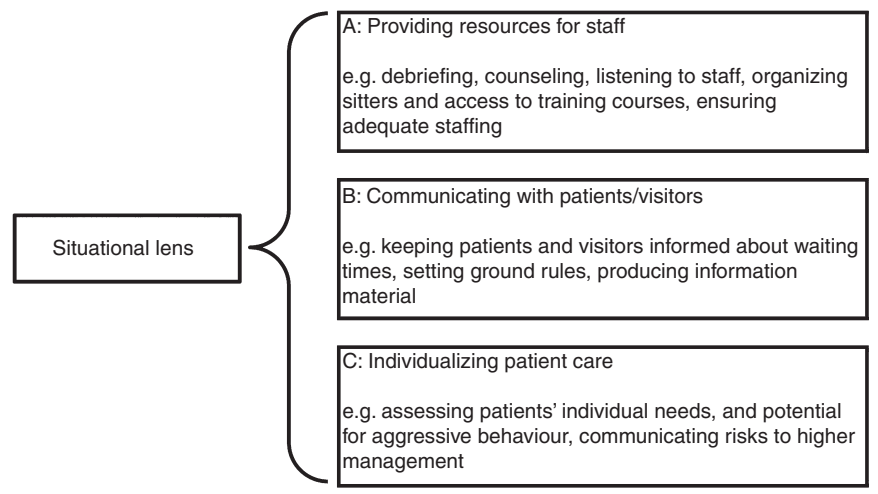

"[...] you really have to keep at it, you have to have really good arguments, not let go, because it is obviously all about the money [...] and it is not like they [hospital management] see why this [PVA] is so important" (IV 4)

Six basic behaviours in the prevention and management of PVA emerged from the analysis:

1. Providing resources for staff

2. Communicating with patients and visitors

3. Individualizing patient care

4. Analysis and reflection

5. Networking with stakeholders outside of the care team

6. Developing work environment and processes.

Behaviours A-C correspond with a view of PVA through the situational lens, behaviours D-F with an organizational view (see Figure 3).

An analysis of relative frequencies of codes showed that the ward managers and divisional managers primarily described behaviours related to the provision of support for staff, while directors of nursing appear to prioritize the development of work environment and care processes (Figure 4).

\section{DISCUSSION}

This paper reports an interview and focus group study with general hospital nurse managers on background factors, determinants, intentions, and behaviours in the prevention and management of PVA. The study was theoretically underpinned by the RAA (Fishbein \& Ajzen, 2010). Three themes emerged from the content analysis. (i) Background factors: PVA is perceived through different lenses; (ii) Determinants and intentions: "Good intentions competing with harsh organizational reality"; (iii) Behaviours: "Preventing and managing aggressive behaviour and relentlessly striving to create safer work environments".

The analysis showed that managers perceive, prevent and manage PVA from a situational and/or organizational perspective, with

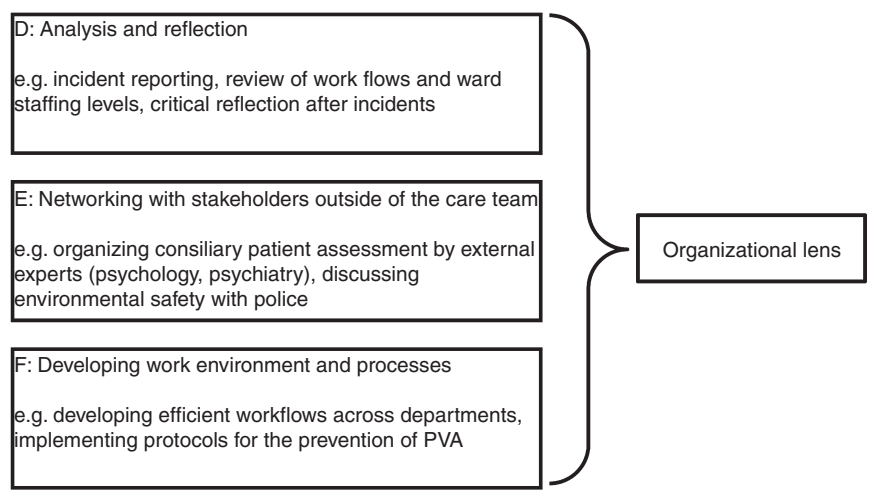

FIGURE 3 Behaviours: management and prevention of PVA 
Leadership position
Behaviour

(most to least frequent)

\section{A: Providing resources}

B: Communicating with patients and visitors

C: Individualizing patient care

D: Networking with stakeholders outside of the care team

\section{$\mathrm{E}$ : Analysis and reflection}

F: Developing work environment and care processes

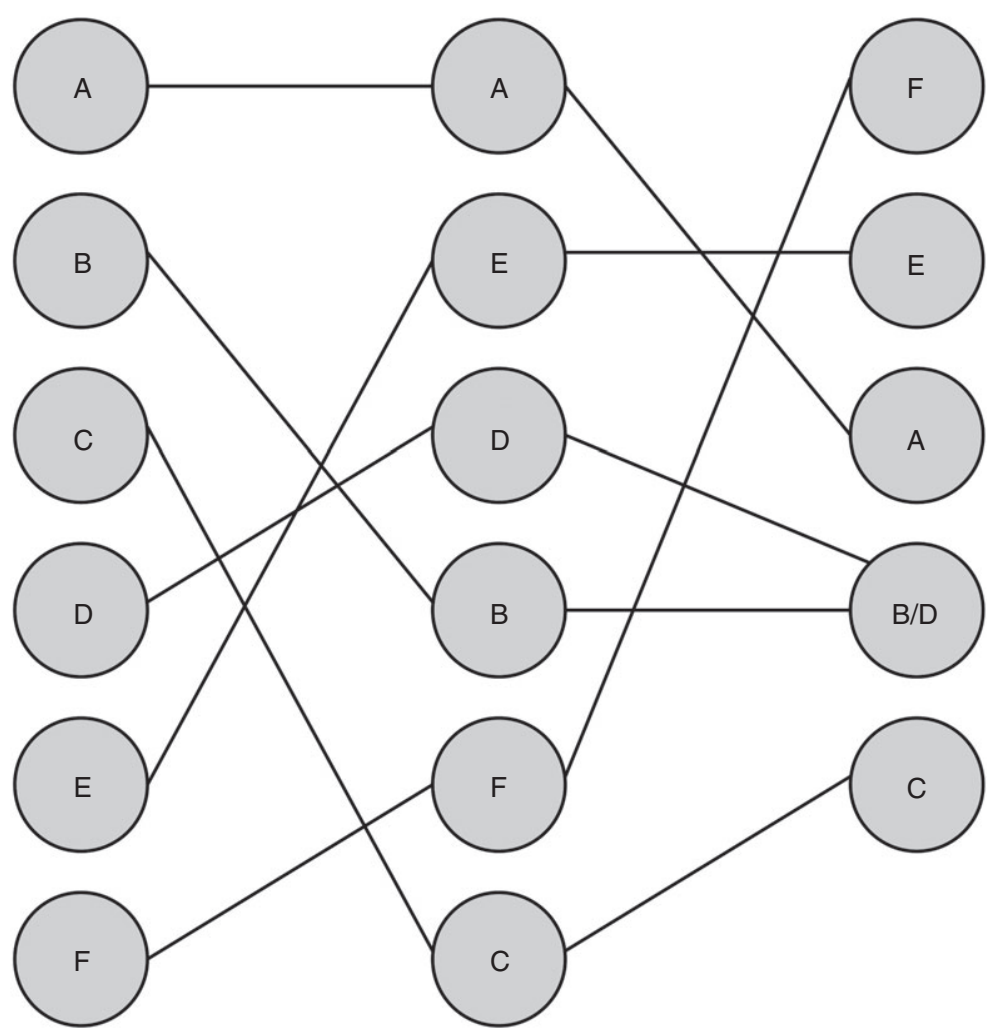

FIGURE 4 Behaviours and leadership positions

each perspective engendering different behaviours. The nurse managers considered PVA an unavoidable, but nevertheless unacceptable part of nursing. They exhibited a positive attitude towards engaging in behaviours to prevent and manage PVA as and when it occurs, at the situational level. They also showed a caring attitude towards their staff and stressed the importance of providing personal, organizational and, if required, external support, such as counsellors after PVA incidents or sitters to ensure close supervision of patients. These findings are in contrast to international evidence reporting that staff nurses lack support from their managers when dealing with PVA. Specifically, staff nurses perceived managers to take the patient's side and favour customer friendliness over staff protection (Gates, Gillespie, Smith, et al., 2011; Renker et al., 2015). They may even be non-respondent or tolerant of PVA (Hegney, Tuckett, Parker, \& Eley, 2010; Shields \& Wilkins, 2009). However, since staff nurses were not included in our study sample, it is not possible to determine whether Swiss managers support their staff to a greater extent than nurse managers in other countries do. Yet our findings may well point towards a gap in the communication of support needs and provision between staff nurses, lower and higher level nurse managers. Currently, verbal communication about PVA between different management levels appears to focus on situational aspects of PVA. Opening a dialogue between nurse managers of all levels and staff to share and discuss mutual expectations, support needs and available resources may facilitate the implementation of more effective measures against PVA. In addition, there is scope to develop PVA incident reporting. The study participants reported that only severe incidents were documented in writing via reporting systems in the organization. Furthermore, the ward managers reported a lack of feedback or action from senior management in response to any written reports. Underreporting of PVA incidents is a wellknown issue that results in an underestimation of the problem and hampers effective action against PVA (Arnetz et al., 2015; Campbell, Burg, \& Gammonley, 2015). A recent study found that $88 \%$ of victims did not officially report the incident and $45 \%$ reported informally to their supervisor (Arnetz et al., 2015). To improve reporting of PVA, it appears to be important not just to make reporting procedures easy (Gates, Gillespie, Smith, et al., 2011), but also to introduce feedback loops to reporting ward managers or staff.

Our analysis showed local differences in the prevalence and implementation of policy and protocols to prevent and manage PVA. While this finding is in line with other international research evidence (Baby, Swain, \& Gale, 2016), it is also reflective of the Swiss healthcare context. Swiss employers are legally obliged to provide employee protection against mobbing and discrimination, yet Switzerland has no legislation explicitly pertaining to aggression in 
health care. Furthermore, in the federal laws and constitution, Swiss hospitals have entrepreneurial freedom and thus organize themselves independently in a competitive, consumer-driven market (Eidgenössisches Departement des Inneren, 2013). Therefore, hospital providers have the freedom, as well as the obligation, to maximize financial profits. Hospitals thus operate with an emphasis on consumer-driven service provision, on saving financial resources and on optimizing care delivery. Nurse managers who want to address PVA at an organizational level therefore find themselves in fierce competition for financial resources. This situation was reflected in our study. Nurse managers perceived their behavioural control to be low due to lack of interest in PVA across the organization and the scarcity of financial resources. This finding is in line with international evidence from nurses and nurse managers reporting organizational management's lack of interest and failure to take action against PVA other than in connection with serious incidents (Gates, Gillespie, Smith, et al., 2011). However, PVA causes delays in care delivery and compromises both staff and patient safety (Arnetz \& Arnetz, 2001; Roche, Diers, Duffield, \& Catling-Paull, 2010, Gates, Gillespie, and Succop, 2011). PVA should therefore be recognized as a threat to the delivery of high quality patient care. Yet the impact of PVA on quality of care and its economical consequences were barely discussed amongst our study participants. This finding might point towards a training need that is at present insufficiently addressed. With a view to the aforementioned competitive, consumer-driven business environment in health care, efforts to raise awareness for PVA at the board level of the organization might be more successful if action against PVA was presented as a business case for improving the quality of care delivery (Swensen, Dilling, Mc Carty, Bolton, \& Harper, 2013). Undeniably, this is a major challenge to nurse managers, as the economical aspects of PVA are to date only insufficiently understood (McKenna, 2008; Rubio-Valera et al., 2015). Furthermore, nurse managers might require training to develop business acumen, as they have been found to rate their financial and budgeting skills lowest amongst their managerial competencies (Kang et al., 2012). Yet nurse managers included in our study were linking clinical practice and organizational management. They were thus in the position to compile the necessary evidence such as the number of PVA incidents, cost incurred, potential savings and benefits (National Institute for Health and Care Excellence, 2015) to put forward action against PVA as a relevant quality improvement initiative and business case at organizational level.

The findings regarding managers' intentions need careful consideration. While attitudes and perceived social norms translated into positive intentions, the perceived behavioural control negatively affected the managers' intentions to address PVA at an organizational level. Yet successful PVA prevention and management requires action at both the situational and organizational level, as well as an all-organizational commitment (Hahn, 2012; McKenna, 2008). Although managers generally expressed a positive intention to address PVA at a situational level, their intentions may not consistently manifest themselves in the described behaviours. Fishbein and Ajzen (2010) highlight that intentions expressed about hypothetical situations, for example in interviews or focus groups, do not necessarily translate into a real-life practice (Fishbein \& Ajzen, 2010). However, this cautious interpretation further underscores the urgent need for support and training. Being able to make a convincing case for addressing PVA in an organization could positively affect and strengthen nurse managers' intentions to act against PVA.

\section{1 $\mid$ Limitations}

Our study has some limitations. The sampling strategy we chose incurs the risk of volunteer bias, as nurse managers who take a particular interest in the topic of aggression will likely be overrepresented. However, we anticipate that working with a sample with this bias will not affect the value of our conclusions: nurse managers who are interested in PVA will provide novel information about the current challenges, opportunities and strategies in the management and prevention of PVA in clinical practice. Another limitation is the potential bias towards socially acceptable answers, as we collected self-reported data. However, we included managers from different managerial levels and this approach produced valuable insights - for example, it highlighted the discrepancy in perceived support between lower and higher management. Some of our data were also analysed quantitatively to identify and compare frequency of codes between different management levels. While this method does not provide information about the statistical significance of our results, the quantitative analysis served to illustrate and describe our qualitative findings. Furthermore, qualitative studies are often perceived to hold limited transferability to wider contexts. However, the nurse managers in this study worked in diverse organizations that were primarily driven by consumer demand and financial considerations. The Swiss situation may therefore serve as a good exemplar for other countries where health care is also driven by economic concerns.

\section{5 | CONCLUSION}

This article presents a content analysis of focus groups and interviews with nurse managers on the prevention and management of PVA in acute hospitals in Switzerland. Nurse managers address PVA at a situational and/or organizational level. The interviews showed that managers feel a strong duty of care towards their staff and a positive attitude and intentions towards behaviours aimed at managing and preventing PVA incidents, i.e., situational management. However, there may be a gap between perceived support provision and actual staff needs. An exploration and exchange of expectations, needs and resources across the nursing team should optimize the collaboration to combat PVA across management levels.

Nurse managers described creating low-aggression environments at the organizational level as a major challenge due to competition for financial resources and lack of organizational support. To increase organizational awareness and support, nurse managers should therefore develop the ability to frame and present patient and visitor aggression as a business case. 


\section{ACKNOWLEDGEMENTS}

We are very grateful to the managers who participated in this study for sharing their experience and their time so generously. We also thank the members of the International Research Collaborative on Clinical Aggression (i-RCCA) for their advice and expert support.

\section{CONFLICT OF INTEREST}

No conflict of interest has been declared by the author(s).

\section{AUTHOR CONTRIBUTIONS}

All authors have agreed on the final version and meet at least one of the following criteria [recommended by the ICMJE (http://www. icmje.org/recommendations/)]:

- substantial contributions to conception and design, acquisition of data, or analysis and interpretation of data;

- drafting the article or revising it critically for important intellectual content.

\section{REFERENCES}

Ajzen, I. (1991). The theory of planned behavior. Organisational Behavior and Human Decision Processes, 50(2), 179-211.

Arnetz, J. E., \& Arnetz, B. B. (2001). Violence towards health care staff and possible effects on the quality of patient care. Social Science and Medicine, 52(3), 417-427.

Arnetz, J. E., Hamblin, L., Ager, J., Luborsky, M., Upfal, M. J., Russell, J., \& Essenmacher, L. (2015). Underreporting of workplace violence: Comparison of self-report and actual documentation of hospital incidents. Workplace Health \& Safety, 63(5), 200-210.

Baby, M., Swain, N., \& Gale, C. (2016). Healthcare managers' perceptions of patient perpetrated aggression and prevention strategies: A cross sectional survey. Issues in Mental Health Nursing, 37(7), 507-516.

Bentley, T., Catley, B., Forsyth, D., \& Tappin, D. (2014). Understanding workplace violence: The value of a systems perspective. Applied Ergonomics, 45(4), 839-848.

Blando, J. D., McGreevy, K., O'Hagan, E., Worthington, K., Valiante, D., Nocera, M., ... Peek-Asa, C. (2012). Emergency department security programs, community crime and employee assaults. The Journal of Emergency Medicine, 42(3), 329-338.

Campbell, C., Burg, M., \& Gammonley, D. (2015). Measures for incident reporting of patient violence and aggression towards healthcare providers: A systematic review. Aggression and Violent Behavior, 25, 314 322.

Catlette, M. (2005). A descriptive study of the perceptions of workplace violence and safety strategies of nurses working in level I trauma centers. Journal of Emergency Nursing, 31(6), 519-525.

Department of Health \& Human Services, State Government of Victoria, Australia (2015) Addressing violence in Victorian healthcare settings. Retrieved from https://www2.health.vic.gov.au/hospitals-and-healthservices/patient-care/acute-care/emergency-care/addressing-violence

Dey, I. (1993). Qualitative Data Analysis: A user-friendly guide for social scientists (1st ed.). London, UK: Routledge.

Edward, K., Ousey, K., Warelow, P., \& Lui, S. (2014). Nursing and aggression in the workplace: A systematic review. British Journal of Nursing, 23(12), 653-659.

Eidgenössisches Departement des Inneren. (2013). Gesundheit 2020. Die gesundheitspolitischen Prioritäten des Bundesrates. [Health 2020. The federal council's health policy priorities]. Bern, Switzerland: Bundesamt für Gesundheit (BAG).

European Agency for Safety and Health at Work. (2002). Violence at work (fact sheet 24). Retrieved from https://osha.europa.eu/en/publi cations/factsheets $/ 24$

Farrell, G., Touran, S., \& Siew-Pang, C. (2014). Patient and visitor assault on nurses and midwives: An exploratory study of employer "protective" factors. International Journal of Mental Health Nursing, 23(1), 8896.

Feather, R., Ebright, P., \& Bakas, T. (2015). Nurse manager behaviors that RNs perceive to affect their job satisfaction. Nursing Forum, 50(2), 125-136.

Fishbein, M., \& Ajzen, I. (1975). Belief, attitude, intention and behavior: An introduction to theory and research (1st ed.). Reading, MA: Addison Wesley.

Fishbein, M., \& Ajzen, I. (2010). Predicting and changing behavior: The reasoned action approach (1st ed.). New York, USA: Taylor \& Francis.

Gates, D., Gillespie, G., Smith, C., Rode, J., Kowalenko, T., \& Smith, B. (2011). Using action research to plan a violence prevention program for emergency departments. Journal of Emergency Nursing, 37(1), 32 39.

Graneheim, U. H., \& Lundman, B. (2004). Qualitative content analysis in nursing research: Concepts, procedures and measures to achieve trustworthiness. Nurse Education Today, 24(2), 105-112.

Hahn, S. (2012). Patient and visitor violence in general hospitals. (Doctoral dissertation) CAPHRI School for Public Health and Primary Care, Maastricht, the Netherlands: Maastricht University.

Hahn, S., Zeller, A., Needham, I., Kok, G., Dassen, T., \& Halfens, R. J. G. (2008). Patient and visitor violence in general hospitals: A systematic review of the literature. Aggression and Violent Behavior, 13(6), 431441.

Hegney, D., Tuckett, A., Parker, D., \& Eley, R. (2010). Workplace violence: Differences in perceptions of nursing work between those exposed and those not exposed: A cross-sector analysis. International Journal of Nursing Practice, 16(2), 188-202.

Kang, C., Chiu, H., Hu, Y., Chen, H., Lee, P., \& Chang, W. (2012). Comparisons of self-ratings on managerial competencies, research capability, time management, executive power, workload and work stress among nurse administrators. Journal of Nursing Management, 20(7), 938-947.

Lanctôt, N., \& Guay, S. (2014). The aftermath of workplace violence among healthcare workers: A systematic literature review of the consequences. Aggression and Violent Behaviour, 19(5), 492-501.

MacQueen, K., McLellan-Lemal, E., Bartholow, K., \& Milstein, B. (2008). Team-based code book development: Structure, process, and agreement. In G. Guest \& K. MacQueen, (Eds.), Handbook for team-based qualitative research (pp. 119-135). Lanham, MD: AltraMira Press.

McKenna, K. (2008). Linking service and safety together creating safer places of service. Strategy for managing work-related aggression and violence within the Irish health service Ireland: Health Service Executive Ireland.

National Institute for Health and Care Excellence. (2015). Costing statement: Violence and aggression. Implementing the NICE guideline on violence and aggression (NG10). Manchester, UK: National Institute for Health and Care Excellence.

Peters, G.-J. Y. (2014). A practical guide to effective behaviour change: How to identify what to change in the first place. European Health Psychologist, 16(5), 142-155. Retrieved from http://ehps.net/ehp/in dex.php/contents/issue/view/ehp.v16.i5/showToc

Renker, P., Scribner, S. A., \& Huff, P. (2015). Staff perspectives of violence in the emergency department: Appeals forconsequences, collaboration and consistency. Work, 51, 5-18.

Roche, M., Diers, D., Duffield, C., \& Catling-Paull, C. (2010). Violence toward nurses, the work environment, and patient outcomes. Journal of nursing scholarship: an official publication of Sigma Theta Tau 
International Honor Society of Nursing/Sigma Theta Tau, 42(1), 13-22. https://doi.org/10.1111/j.1547-5069.2009.01321.x

Rubio-Valera, M., Luciano, J., Ortiz, J., Salvador-Carulla, L., Gracia, A., \& Serrano-Blanco, A. (2015). Health service use and costs associated with aggressiveness or agitation and containment in adult psychiatric care: A systematic review of the evidence. BMC Psychiatry, 15(35),

Sandelowski, M. (2000). Whatever happened to qualitative description? Research in Nursing \& Health, 23(4), 334-340.

Schreier, M. (2012). Qualitative content analysis in practice (1st ed.). London, UK: SAGE Publications Ltd.

Schreier, M. (2014). Varianten qualitativer Inhaltsanalyse: Ein Wegweiser im Dickicht der Begrifflichkeiten. [Ways of Doing Qualitative Content Analysis: Disentangling Terms and Terminologies]. Forum Qualitative Sozialforschung/Forum: Qualitative Social Research, Vol. 15. Retrieved from http://nbn-resolving.de/urn:nbn:de:0114-fqs1401185

Shields, M., \& Wilkins, K. (2009). Factors related to on-the-job abuse of nurses by patients. Health reports, 20(2), 7-19. Retrieved from http:// www.statcan.gc.ca/pub/82-003-x/2009002/article/10835-eng.pdf

Spector, P. E., Zhou, Z. E., \& Che, X. X. (2014). Nurse exposure to physical and nonphysical violence, bullying and sexual harassment: A quantitative review. International Journal of Nursing Studies, 51(1), 72-84.

Swensen, S. J., Dilling, J., Mc Carty, P., Bolton, J., \& Harper, C. (2013). The business case for health-care quality improvement. Journal of Patient Safety, 9(1), 44-52.

The Health and Safety Executive (2015a). Violence at work 2013/14. Findings from the Crime Survey for England and Wales. Retrieved from http://www.hse.gov.uk/STATISTICS/causinj/violence/violenceat-work.pdf

The Health and Safety Executive. (2015b). Violence in health and social care. Retrieved from http://www.hse.gov.uk/healthservices/violence/
The National Audit Office. (2003). A safer place to work. Protecting NHS hospital and ambulance staff from violence and aggression.Retrieved from https://www.nao.org.uk/report/a-safer-place-towork-protecting-nhs-hospital-and-ambulance-staff-from-violence-andaggression/

Wolf, L., Delao, A., \& Perhats, C. (2014). Nothing changes, nobody cares: Understanding the experience of emergency nurses physically or verbally assaulted while providing care. Journal of Emergency Nursing, 40 (4), 305-310.

\section{SUPPORTING INFORMATION}

Additional Supporting Information may be found online in the supporting information tab for this article.

How to cite this article: Heckemann B, Peter KA, Halfens RJG, Schols JMGA, Kok G, Hahn S. Nurse managers:

Determinants and behaviours in relation to patient and visitor aggression in general hospitals. A qualitative study. J Adv

Nurs. 2017;73:3050-3060. https://doi.org/

$\underline{10.1111 / j a n .13366}$

The Journal of Advanced Nursing (JAN) is an international, peer-reviewed, scientific journal. JAN contributes to the advancement of evidencebased nursing, midwifery and health care by disseminating high quality research and scholarship of contemporary relevance and with potential to advance knowledge for practice, education, management or policy. JAN publishes research reviews, original research reports and methodological and theoretical papers.

For further information, please visit JAN on the Wiley Online Library website: www.wileyonlinelibrary.com/journal/jan

Reasons to publish your work in JAN:

- High-impact forum: the world's most cited nursing journal, with an Impact Factor of 1.998 - ranked 12/114 in the 2016 ISI Journal Citation Reports $\odot$ (Nursing (Social Science)).

- Most read nursing journal in the world: over 3 million articles downloaded online per year and accessible in over 10,000 libraries worldwide (including over 3,500 in developing countries with free or low cost access).

- Fast and easy online submission: online submission at http://mc.manuscriptcentral.com/jan.

- Positive publishing experience: rapid double-blind peer review with constructive feedback.

- Rapid online publication in five weeks: average time from final manuscript arriving in production to online publication.

- Online Open: the option to pay to make your article freely and openly accessible to non-subscribers upon publication on Wiley Online Library, as well as the option to deposit the article in your own or your funding agency's preferred archive (e.g. PubMed). 